\title{
THE PERFORMANCE ANALYSIS OF MULTI- USER WCDMA SYSTEMS USING D-STBC IN RAYLEIGH FADING CHANNEL
}

\author{
Ali Muayyadi ${ }^{1}$, Gelar Budiman ${ }^{2}$, Rina Pudji Astuti ${ }^{3}$ \\ 1,2,3: Dept of Electrical \& Communication Engineering, Telkom Engineering School, Telkom University \\ Jl.Telekomunikasi, Bojongsoang, BANDUNG, INDONESIA \\ alimuayvadi@telkomuniversity.ac.id $^{1}$, glb@ittelkom.ac.id ${ }^{2}, \underline{\text { rpa@ittelkom.ac.id }}{ }^{3}$
}

\begin{abstract}
The development of wireless communication systems is focusing to provide a link with a high capacity and good quality. The multi-hop communication system using relay's diversity with a reliable coding is designed to fulfil the above requirements.

Using multi-user WCDMA system, this research applies the above multi-hop technique using a relay with Alamouti code which can be defined as Distributed- Space Time Block Code or D-STBC. Therefore it does not need multi antenna but act like MIMO and that is why it is also called virtual MIMO using a cooperative multi-hop system.

The simulation results show that the $2 \times 1$ virtual MIMO multi hop system performs better than a single hop system. Targeting BER of $10^{-3}$, the multi hop system give $12 \mathrm{~dB}$ gain compared with a single hop system.
\end{abstract}

Keywords - Alamouti, STBC, DSTBC, Multi-Hop System, Relay's Diversity, Virtual MIMO

\section{INTRODUCTION}

The development of wireless communication systems is focusing to provide a link with a high capacity and good quality. The high capacity is required to support multimedia services such as voice, image, data and video. Moreover, the communication link must have a good quality meaning it can achieve low bit error rate using low power. On the other hand, the radio resource is limited, and the wireless communications have complex channel characteristic which is usually modeled as Rayleigh fading channel.

One method to improve capacity and quality is using multi antenna system, known as Multiple Input Multiple Output (MIMO). One of MIMO transmission techniques often used is Space Time Block Code (STBC) found by Siavash M. Alamouti [1]. This STBC technique relies on code orthogonality, so that the correlation between the antennas would be almost zero and therefore has an impact to better quality compared with non STBC system [1].

The STBC method was then extended to apply in the cooperative communications with multi hop which can improve the system transmission performance significantly even with single-antenna [2] and known as Distributed-STBC (D-STBC). Using multi-user WCDMA system, this research applies D-STBC.to cooperative communication with single antenna on the Rayleigh fading channels and uses 3 hops for the simulation.

\section{SYSTEM MODEL}

The communication between transmitter and receiver is performed in 2 paths (direct path and via relay). There are 3 hops,i.e. base station (BS) - relay, relay - mobile station (MS), and BS - MS.

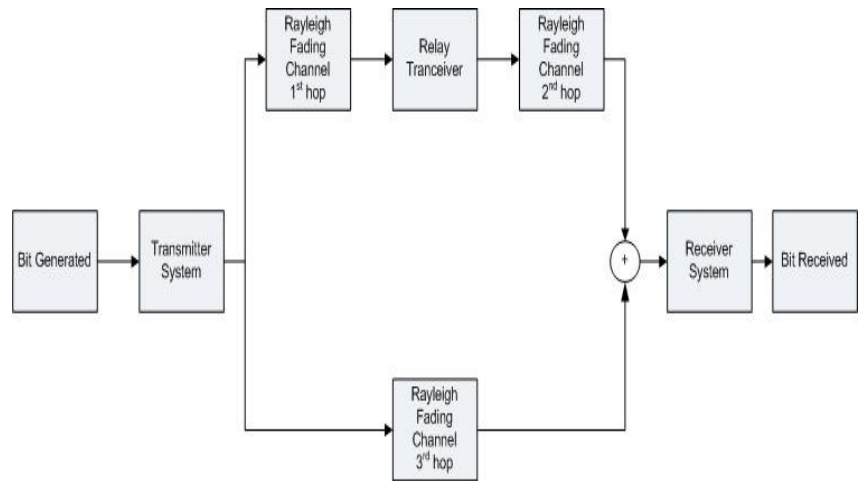

Figure 1. One relay (3 hops) model system using single antenna

The WCDMA transmitter system includes the process of convolutional coding, interleaving and modulation (represented by mapper here) as shown in Figure 2.

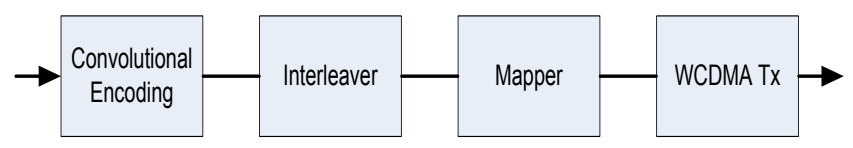

Figure 2. Transmitter system

The relay system used here is a decode-and-forward type as depicted in Figure 3. below.

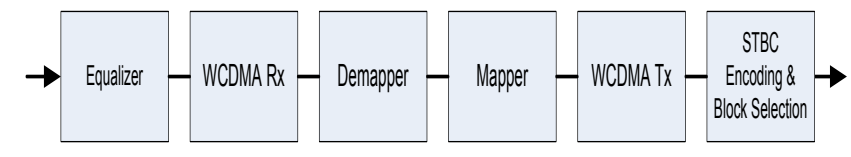

Figure 3. Relay system model 
Figure 4 illustrates the WCDMA receiver system which includes the process of synchronization, STBC decoding, deinterleaving, demodulation and viterbi decoding.

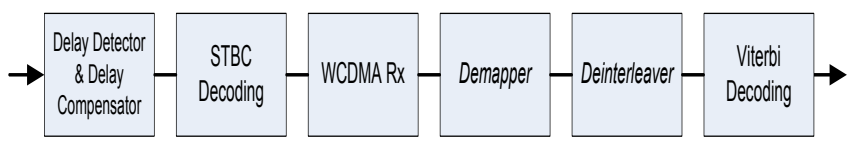

Figure 4. Receiver system

\section{$2.1 \quad$ Basic STBC}

Orthogonal Space Time Block Code (STBC) is transmission scheme introduced by Alamouti using $2 \times 2$ or $2 \times 1$ antenna as shown in Figure 5 below.

$$
t+\left[\begin{array}{cc}
T_{x 0} & T_{x 1} \\
S_{0} & S_{1} \\
-S_{1}^{*} & S_{0}^{*}
\end{array}\right]
$$

Figure 5. Orthogonal space time block code transmission scheme [1]

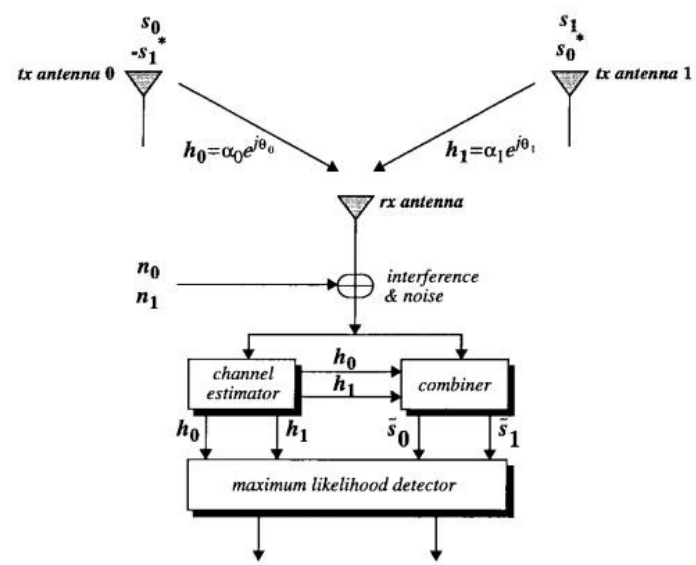

Figure 6. MIMO scheme using $2 \mathrm{Tx}$ antenna and $1 \mathrm{Rx}$ antenna (2x1) [1]

The channel at time $t$ is modeled by a complex multiplicative coefficient $\boldsymbol{h}_{\boldsymbol{0}}(t)$ from $1^{\text {st }}$ transmitter antenna and $\boldsymbol{h}_{\boldsymbol{l}}(t)$ from $2^{\text {nd }}$ transmitter antenna. Assuming that fading coefficients are constant across two consecutive symbols as :

$$
\begin{aligned}
& \boldsymbol{h}_{0}(t)=\boldsymbol{h}_{0}(t+T)=\boldsymbol{h}_{0}=\alpha_{0} e^{j \theta_{0}} \\
& \boldsymbol{h}_{\mathbf{1}}(t)=\boldsymbol{h}_{\mathbf{1}}(t+T)=\boldsymbol{h}_{\mathbf{1}}=\alpha_{1} e^{j \theta_{1}}
\end{aligned}
$$
be written as :

Derived from Figure 5 and 6, the received signal can

$$
\begin{gathered}
\boldsymbol{r}_{0}=\boldsymbol{r}(t)=\boldsymbol{h}_{0} \boldsymbol{s}_{0}+\boldsymbol{h}_{1} \boldsymbol{s}_{1}+\boldsymbol{n}_{0} \\
\boldsymbol{r}_{\mathbf{1}}=\boldsymbol{r}(t+T)=-\boldsymbol{h}_{0} \boldsymbol{s}_{1}^{*}+\boldsymbol{h}_{1} \boldsymbol{s}_{0}^{*}+\boldsymbol{n}_{\mathbf{1}}
\end{gathered}
$$

$\boldsymbol{n}_{0}$ and $\boldsymbol{n}_{1}$ are complex random variable which represents interference and noise thermal.

The combiner subsystem in Figure 6 will decode the received signal as follows:

$$
\tilde{s}_{0}=h_{0}^{*} r_{0}+h_{1} r_{1}^{*}
$$

$$
\tilde{s}_{1}=h_{1}^{*} r_{0}-h_{0} r_{1}^{*}
$$

Substituting equation 1 to 3 will give the following result :

$$
\begin{aligned}
& \tilde{\boldsymbol{s}}_{0}=\left(\alpha_{0}^{2}+\alpha_{1}^{2}\right) \boldsymbol{s}_{\mathbf{0}}+\boldsymbol{h}_{0}^{*} \boldsymbol{n}_{\mathbf{0}}+\boldsymbol{h}_{\mathbf{1}} \boldsymbol{n}_{\mathbf{1}}^{*} \\
& \tilde{\boldsymbol{s}}_{\mathbf{1}}=\left(\alpha_{0}^{2}+\alpha_{1}^{2}\right) \boldsymbol{s}_{\mathbf{1}}-\boldsymbol{h}_{\mathbf{0}} \boldsymbol{n}_{\mathbf{1}}^{*}+\boldsymbol{h}_{\mathbf{1}}^{*} \boldsymbol{n}_{\mathbf{0}}
\end{aligned}
$$

\begin{tabular}{c|c|c}
\cline { 2 - 3 } & antenna 0 & antenna 1 \\
\hline time $t$ & $s_{0}$ & $s_{1}$ \\
\hline time $t+T$ & $-s_{1}{ }^{*}$ & $s_{0}{ }^{*}$ \\
\hline
\end{tabular}

Figure 7 The received signal in $2 \times 1$ scheme [1]

\subsection{Distributed Space Time Block Code (D-STBC)}

The application of STBC in cooperative communications using multi hop system can improve the system transmission performance significantly even with single-antenna [2]. This technique is called the DistributedSTBC (D-STBC) or virtual MIMO and shown in Figure 8.

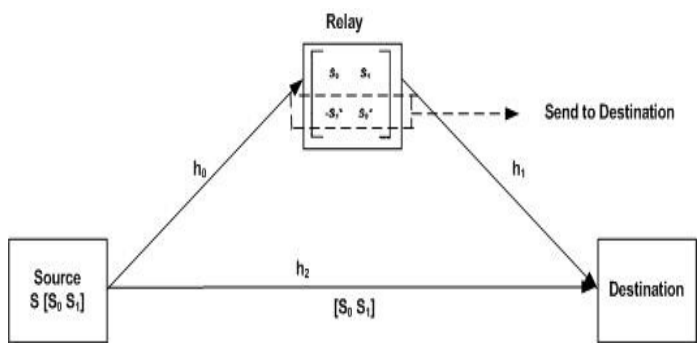

Figure 8 Cooperative communications using D-STBC technique

The D-STBC decoder applies the same method as STBC decoder using the Equation 3 and 4 aforementioned.

\section{RESULTS AND ANALYSIS}

The system model and simulation assume the following items:

- The channel is Rayleigh i.i.d

- Perfect channel estimation

- Single antenna in each element

- Speed of relay is assumed equal to the speed of MS (as an MS can become a relay).

\subsection{SISO vs D-STBC Scheme}

The BER performance of SISO and D-STBC scheme is given in Figure 9. Here the system uses BPSK modulation and the speed of MS and relay is $30 \mathrm{~km} / \mathrm{h}$ relatively to each other and to BS. Targeted BER of $10^{-3}$ SISO system should require $\mathrm{Eb} / \mathrm{No}$ of $29 \mathrm{~dB}$ while $\mathrm{D}$ STBC (3 hops) system only needs about $17 \mathrm{~dB}$. And therefore D-STBC get $12 \mathrm{~dB}$ gain compared with SISO system. 


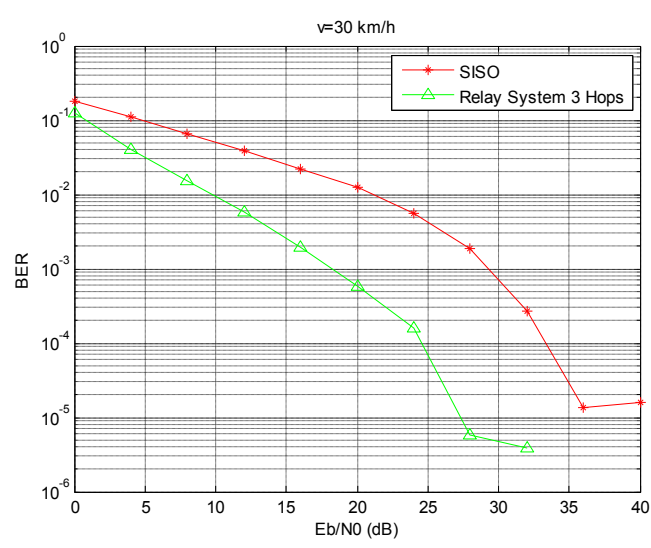

Figure 9 BER performance for SISO and D-STBC system

\subsection{Impact of Speed}

In order to see the impact of channel variation caused by the movement of MS as well as relay, the simulation is performed using WCDMA system with a spreading factor of 16. The simulation result is given in Figure 10 . Obviously when the MS and relay is stationary, the BER performance is much better than the ones with the speed above $30 \mathrm{~km} / \mathrm{h}$.

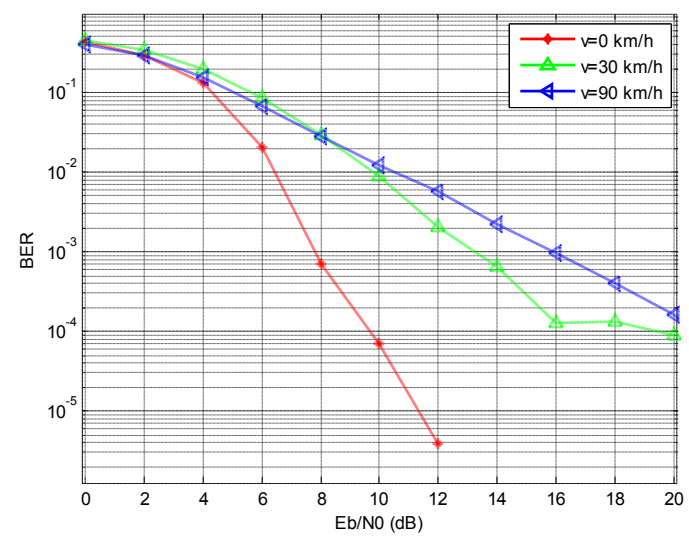

Figure 10. BER performance varied with MS and relay speed

\subsection{Impact of Frequency Selectivity}

In order to see the impact of channel frequency selectivity caused by the different channel delay, the simulation is performed using WCDMA system with a spreading factor of 32. The simulation result is given in Figure 11 . Obviously when the channel fading is flat, the BER performance is much better than the ones with the delay ( 1 and 10 symbol period delay for selective fading and more selective fading channel respectively).

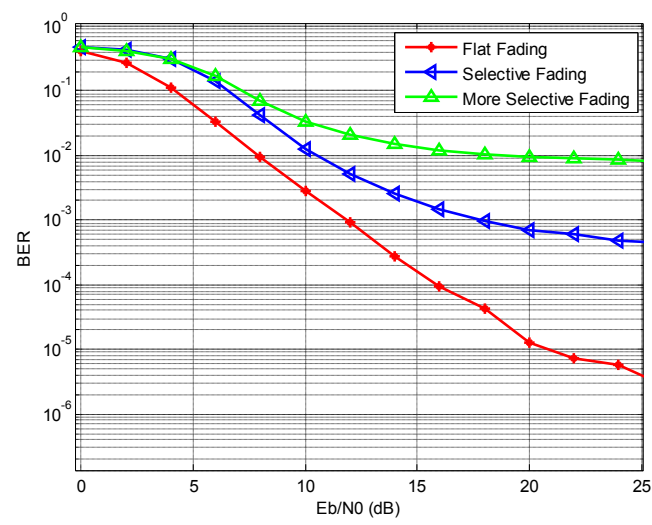

Figure 11. BER performance varied with channel delay

\subsection{Impact of Spreading Factor}

The different hop delay without further compensation will destroy the orthogonality which in turn gives poor BER performance, This can be seen in Figure 12 when the system is without Rake receiver. On the other hand we can see the impact of spreading factor to BER performance. Obviously the higher the spreading factor the better the BER performance.

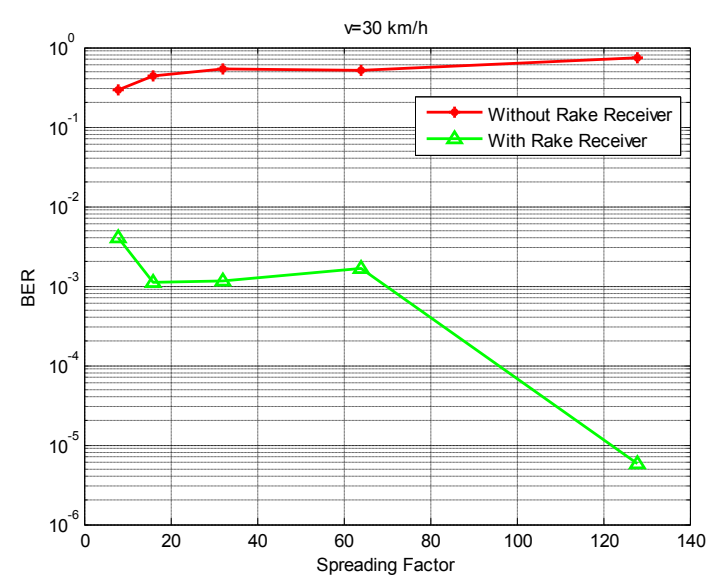

Figure 12. BER versus spreading factor.

\subsection{Impact of Number of Users}

Figure 13 gives an illustration about the impact of number of users. The simulation is performed using WCDMA system with a spreading factor of 64 and difference of hop delay of 3 symbol period.. As the system is without multi user detection (MUD) method when the number of users is higher, obviously the BER performance is poorer. 


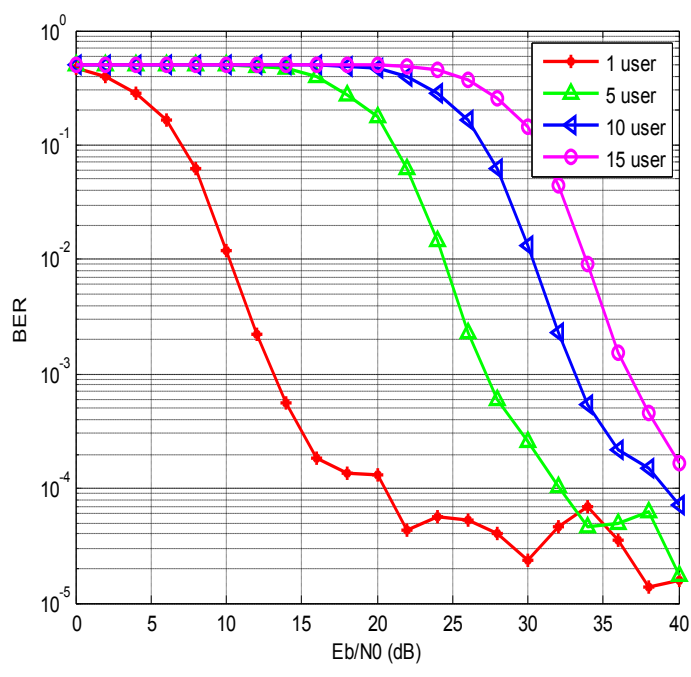

Figure 13. BER performance varied with number of users

\section{Conclusions}

A multiuser WCDMA system using D-STBC multihop has been simulated and analysed. It shows that the D-STBC system (3 hops) gain $12 \mathrm{~dB}$ better than single hop system. The different hop delay without further compensation will destroy the orthogonality of D-STBC signal which in turn gives poor BER performance. The Rake receiver will compensate this different hop delay. The D-STBC system performance drop as the MS or relay move above. $30 \mathrm{~km} / \mathrm{h}$ and the system has to power up $13 \mathrm{~dB}$ to reach the same quality as stationary condition.

Further developing system applying multi user detection (MUD) will give better BER performance. Developing system with multi antenna scheme at the transmitter and receiver might give better performance.

\section{ACKNOWLEDGMENT}

The authors would like to thank Directorate General of Higher Education and Telkom University for their support and research grant.

\section{REFERENCES}

[1] SM. Alamouti, "A Simple Transmit Diversity Technique for Wireless Communication", IEEE Journal on Selected Areas in Communication, vol 16 No.8, October 1998

[2] W. Jaafar , "On the Performance of Distributed-STBC in Multi-hop Wireless Relay Networks", IEEE European Wireless Conference, 2010.

[3] R. Vaze and R.W. Heath, "Cascaded orthogonal space-time block codes for wireless multi-hop relay networks", EURASIP Journal On Wireless Communication and Networking, Springer, 2013.

[4] Borah D.K, Moreno Crespo, Nammi S., "Distributed Alamout Transmit Diversity Technique for Co-Operative Communication", Vehicular Technology Conference Proceeding, 2007. VTC2007-Spring. IEEE $65^{\text {th }}$, Dublin, 2007.
[5] J. Proakis, "Digital Communications", McGraw Hill, 3rd., 1995.

[6] David Gesbert, Mansoor Shafi, Da-Shan Shiu, Peter J. Smith, Ayman Naguib, "From Theory to Practice : An Overview of MIMO SpaceTime Coded Wireless Systems", Tutorial Paper, IEEE Journal On Selected Areas In Communication Vol. 21, No.3 April 2003, Oslo University, Norway.

[7] Gelar Budiman, Ali Muayyadi, Rina Pudji Astuti, "Single Relay Cooperative System Based On Two Scheme of Alamouti Block Code In Rayeleigh Fading Channel", Jurnal Telekomunikasi IT Telkom Juni 2013 Volume-17 No. 2 ISSN : No. 1410-7066, ITTelkom, 2013.

[8] S.Alabed, M.Pesavento, "Non-Coherent Distributed Space-Time Coding Techniques for Two-Way Wireless Relay Networks", SciVerse Science Direct in Signal Processing, 2012.

Ali Muayyadi is a member of IEEE. He finished his BEng degree in electrical engineering from ITB, Bandung, Indonesia in 1990,

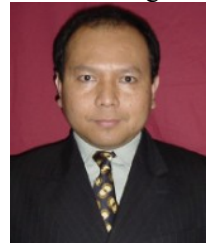

MSc degree in mobile communicate ons from ENST, Paris in 1997 and $\mathrm{PhD}$ degree in digital communications from University of Plymouth, UK in 2003 .

Now he is the head of department of electrical and communications, Telkom engineering school, Telkom university, Bandung, Indonesia.

His research interests are mainly in wireless and mobile communications, such as multicarrier modulation, LTE, 4G and beyond, multiple access, MIMO, mobile traffic and networks. 